\title{
EXPLORING THE ADOLESCENTS' ATTITUDE TOWARDS JUNK FOOD IN TIRUVANNAMALAI
}

\author{
S. Shafiullah ${ }^{1 \rrbracket}$, Dr. R. Sivakumar ${ }^{2}$ \\ ${ }^{1}$ Research Scholar, Department of Business Administration, Annamalai University, India \\ ${ }^{2}$ Assistant Professor, Department of Business Administration, Government Arts and Science College, \\ Kulithalai, India
}

Received 20 July 2021

Accepted 07 August 2021

Published 30 September2021

CorrespondingAuthor

S. Shafiullah,

assistantprofessor.au@gmail.com

DOI

10.29121/granthaalayah.v9.i9.2021. 4152

Funding: This research received no specific grant from any funding agency in the public, commercial, or not-for-profit sectors.

Copyright: (C) 2021 The Author(s). This is an open access article distributed under the terms of the Creative Commons Attribution License, which permits unrestricted use, distribution, and reproduction in any medium, provided the original author and source are credited.

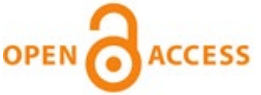

\section{ABSTRACT}

The term fast food or as referred as the junk food is the food which can be served immediately for eating. Sausages, hamburgers and pizzas come under the category of fast food or the junk food. It can be otherwise said that junk food and fast food are used as synonyms. These junk foods are inherent with a high level of energy with high content of sugar, salt and fat. On the contrary, these types of food have the characteristics of low nutritious level with low level of protein, low level of vitamin, low fibre content as well as low level of minerals. The definition for junk food had been given as the foods which are prepared earlier then served or the ones which are prepared immediately for serving. In this context, the current research study has been done to analyse the adolescent's attitude towards the junk foods. The study has been carried out the junk food consumers in Tiruvannamalai. The respondents of the study are selected through convenience sampling and the sample size is fixed at 100. Questionnaire is the instrument used to collect the information for the study. The collected data is put into analysis through the technique of mean score. The result of the study shows that most of adolescents like the taste of junk food.

Keywords: Adolescent; Attitude; Junk Food

\section{INTRODUCTION}

The period of adolescence refers to the time period in the life of an individual during which the physical development of the person improves or increases. The immediate growth at the time of adolescence is related with the emotional, cognitive and hormonal changes which makes the adolescence period a vulnerable time in the life of a person.During this time period, the physical body of a person needs high level of calories as well as nutrients because of the improvements in the physical development and growth at this period of time. Next, the adolescence period is the period where the individual makes a change in his/her lifestyle as well as the food habits which makes an influence over the intake and needs for the nutrients. The period of adolescents is featured by a high level of demands for proteins and calories. During this time period, the appetite of a person gets increased and the person wishes to eat food which is high rich in carbohydrates. The improper eating habits of consuming more snacks may lead to low level of intake of the vitamins A and C. now-a-days, many people have become health-conscious and have also started to minimize or avoid on the whole, the junk food. Despite of this awareness among the people, several manufacturers of food produce products which come under the category of junk. 
foods. Several health officials, doctors and nutritionist are continuously work to make the people aware of the ill-effects of junk foods. They also educate the people about a balanced diet essential for a healthy life. This balanced diet is the food which is filled with all the nutrients in high proportion.

The junk food most commonly influences the food habits of a child. Junk foods affects the health of a child in many negative ways. These junk foods lead to problems like cancer, diabetes, heart disease and high level of blood pressure. Studies on junk food show that consumption of junk foods lead to the clogging of arteries even at the age of 30 which finally leads to heart attack. Hypertension and osteoporosis are few other problems caused by the continuous consumption of fast foods. A diet which is not rich in all the nutrients affects the growth of a child, leads to tooth decay, causes obesity and so on. To be short, junk foods are the ones which do not possess the calories needed for an individual.

Changes in the lifestyle of the society, and adolescents in particular, have increased the needs to follow the practice of consuming nutritious foods. The benefits of nutritious food and ill-effects of junk foods have to be included in the educational curriculum so as to make the adolescents aware of their health and also healthy survival. Healthy nutrition has to be given first preference and hence the adolescents have to be aware of the fact that their eating habits affects their health. They should also know the way they grow, what they feel and how they behave. The so-called junk foods or the fast foods are the ones which are produced or made with a huge quantity of saturated fats which proves to be unhealthy for the human health as well as creates a lot of toxic elements in the body. Further, junk food also is deficient in minerals and vitamins which are essential for building immunity in the body as well as for good health. The habits of eating food are established by the taboos, prejudices and attitude that are practices in the early period of life. It is a general practice seen among the adolescents they consume more amount of junk foods which are not accepted or approved by the senior members of their family. Adolescents form typical likes as well as dislikes for foods. They have the tendency to consume high quantity of junk foods like burgers, noodles, hot dogs, sandwiches carbonated drinks chips pastries, popcorn etc., and this practice can be seen as a common feature of the diet of an adolescent [Singh and Singh (2008)]

\section{Statement of problem}

The period of teenage or the adolescence is generally related with the search for lifestyle changes, identity and independence. The adolescent people are more and more addicted towards the junk food. This increased junk food consumption has become a crucial issue of adolescent health concern and needs an urgent measure to be undertaken for solving this issue of adolescent health.

\section{Objectives}

The main aim of the study is to explore the attitudes of the adolescents towards the fast food or the junk food products in Tiruvannamalai.

\section{REVIEW OF LITERATURE}

Sapkota and Neupane (2018) had explored the consumption of junk food amongst the students of secondary level. The study was done in Chitwan. The author had stated that junk food is the identical term used for cheap food. It contains extreme levels of sugar and fat with low levels of minerals, vitamins, protein and fibre. The authors had performed this research study for evaluating the consumption pattern of the junk foods among the students of secondary level 
school. They had done a cross-sectional study which was also descriptive in nature. The respondents for the study were selected through cluster sampling and the sample size was 142. The tool used for data collection was a questionnaire which was semi-structured and self-administered in nature. The analysis of the data was done using SPSS v.20 and Epi-data with the help of the methods of simple statistics. The findings of the study showed that when the boys and girls were compared, it was the girls who consumed more junk foods, though knowing the bad effects of junk foods. The reason for preferring junk food were taste, easy and less-time consuming for preparation, influence by peer and television. The most preferred junk foods among the respondents were noodles, chat-pats, doughnuts, pani-puri, biscuits, chocolates, cold-drinks and ice-creams. It was concluded by the authors that adolescents had got a great level of consumption of junk foods which paved the way to bad-effects on health. Recommendations were given by the authors that the community and schools have to conduct as well as implement the program for awareness regarding the bad effects of consuming junk foods.

Haimanot et al. (2018) studied the factors which influenced the choice of consumers for the fast foods and the street foods. The study was done in China. The purpose of the authors was to analyse the outcomes in the field of the attitudes and behaviours of consumers regarding the fast foods and the street foods as well as the related ill-effects in the consumption of those foods, in reference to the Chinese people. In recent days, the consumption of junk foods or the fast foods had become a common trend and is considered as the indicator of modernity in many nations. These fast foods are generally preferred by the Chinse people because of the safety issue, easy availability, reasonable price, portability etc. the Chinese government had started to practice the FSL (food safety law) and the FHL (food hygiene law) as a measure for ensuring the food safety. The findings of the study showed that the consumers of fast foods in China give preference to quality and safety of food than the price.

Atanda and Dane (2020) explored the attitude of the consumers towards the junk foods. The study was done among the students of a private university in Nigeria. The study had been done according to the academic level, gender, and the marital status of the participants. The consumption of fast foods leads to diabetes, obesity, hypertension and mellitus. The respondents of the study were 145 male students and 177 female students, which comprised the sample size of 322 . All the participants were at the age of 18-26. The data collection tool was a questionnaire. It was explored by the authors that the Nigerian boys consumed a lot of junk foods when compared with the girls. The main factors supporting the consumption of fast foods were variety, convenience and easy and less-time consuming for preparation. It was concluded that the consumption of fast food was high in Nigeria among the adolescents. This trend was predicted to lead to hypertension, obesity, mellitus and diabetes.

\section{RESEARCH METHODOLOGY}

The study has been done in the Tiruvannamalai area with regard to the attitudes exhibited by the adolescents towards the consumption of junk foods. The respondents are selected through continence Sampling. The participants of the study are requested to fill in a questionnaire for the purpose of getting the required information of the study. The collected data is put into analysis through mean score. 


\section{ANALYSIS AND INTERPRETATION}

ATTITUDE TOWARDS JUNK FOOD

Mean

Item1: I will become obese if I eat junk food.

Item2: The consumption of junk food will make me famous.

Item3: The taste of junk food is very good.

Item4: Consumption of junk food gives me pleasure.

Item5: Consumption of junk food gives me enough time for doing other work.

Item6: Junk foods are very cheap.

Item7: Junk foods increase the fat content in my body.

Item8: The consumption of Junk food is the method of enjoyment with friends outside.

Item9: It is easy to consume Junk food.

Item10: Junk foods are good for health.

\section{Graphical representation of Attitude}

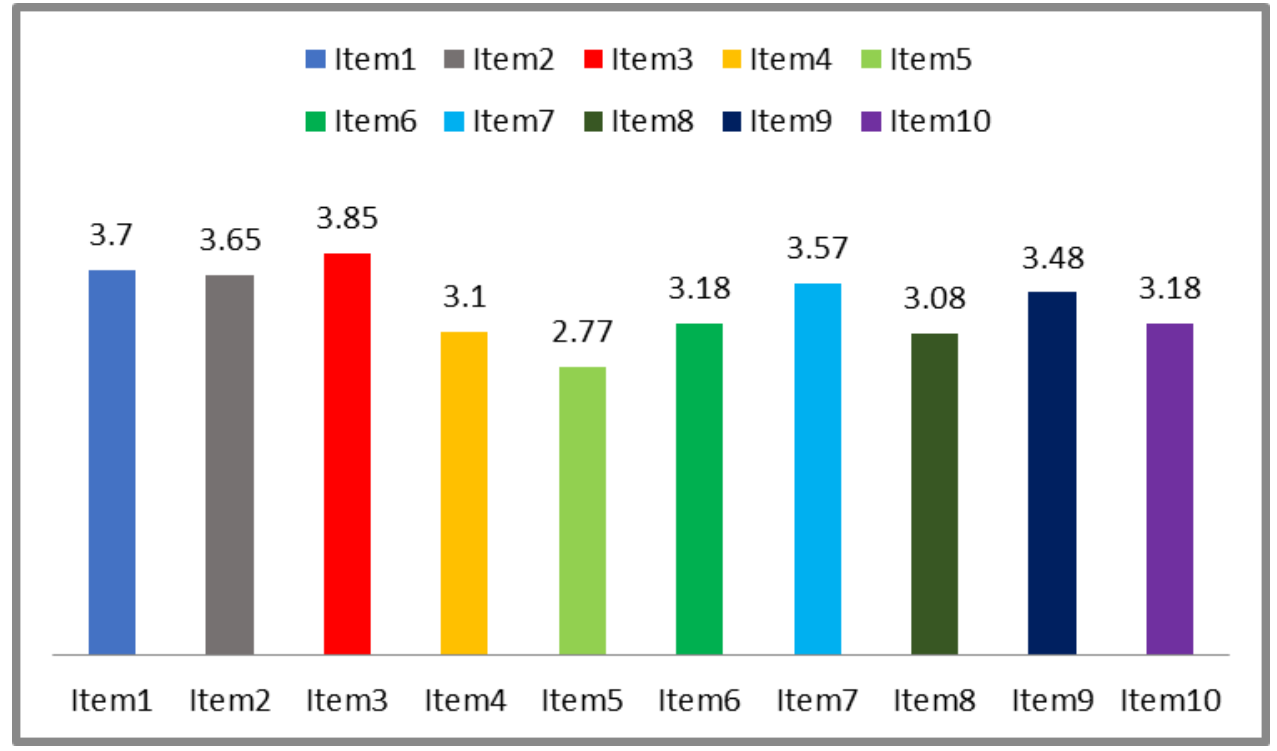

Figure 1

The Adolescents' attitude was investigated through questions. The table shows that the respondents who stated that "Consumption of junk food gives me pleasure.." have the highest mean value of 3.85. Next to that the respondents who stated that "I will become obese if I eat junk food" have the mean value of 3.70. The respondents who stated that "Consumption of junk food gives me enough time for doing other work." have the least mean value of 2.77. The result of the study shows that most of adolescents like the taste of junk food

\section{CONCLUSION}

In recent times, the consumption of fast foods can be seen to increase among the adolescents. The high consumption of junk foods or the fast foods paves the way 
to high level of obesity, diabetes and hypertension. Junk foods affects the health of all the individuals, and in specific the health of the adolescents. Hence, it becomes essential to make them aware of the bad effects of consuming junk foods. Awareness programs should be conducted in schools and also by the government to teach them our (Indian) traditional way and pattern of consumption of food and their benefits. The result of the study shows that most of adolescents like the taste of junk food

\section{REFERENCES}

Haimanot B. Atinkut, Yan Tingwu, Bekele Gebisa, Shengze Qin, Kidane Assefa, BirukYazie, Taye Melese, Solomon Tadesse and TadieMirie (2018); Factors influencing consumers' choice of street-foods and fast-foods in China; African Journal of Marketing Management; Vol. 10(4), pp. 28-39, November 2018. Retrieved from https://doi.org/10.5897/AJMM2018.0572

Omolola Atanda, Senol Dane (2020), Attitude Towards Fast Food Consumption Among Students in a Private Nigerian University by Gender, Academic Level, and Marital Status, J Res Med Dent Sci, 8 (3):248-252. Retrieved from https://www.jrmds.in/articles/attitude-towards-fast-food-consumptionamong-students-in-a-private-nigerian-university-by-gender-academiclevel-and-marital-status-53927.html

Shubha devi Sapkota and Seema Neupane (2018) Junk Food Consumption Among Secondary Level Students, Chitwan; Journal of Nepal Paediatric Society. 37. 147. Retrieved from https://doi.org/10.3126/jnps.v37i2.17081

Singh, P. and Singh, A. (2008). Increasing allurensent for fast food in adolescent girls of urban area Varanasi. Ind J Prev Soc Med, 39 (1and 2): 24-27 